Artículo de investigación científica y tecnológica

Cómo citar: S. Reginfo y M. Rico.

“Jardín infantil Na'e Dwshu. Un environmental, cultural and technological business design

with a person-centered pedagogical approach,

in The Hormiga, Putumayo". Inventum,

vol. 15, no. 29, pp. 95-116. doi: $10.26620 /$

uniminuto.inventum.15.29.2020.95-116

Editorial: Corporación Universitaria Minuto de Dios - UNIMINUTO.

ISSN: $1909-2520$

elSSN: $2590-8219$

Fecha de recibido: Mayo 15 de 2020

Fecha de aprobado: Junio 15 de 2020

Fecha de publicación: Julio 15 de 2020

Conflicto de intereses: los autores han declarado que no existen intereses en competencia.

Stella Rengifo Meneses

srengifo@unbosque.edu.co

ORCID https://orcid.org/0000-0003-1587-5160.

Universidad El Bosque

Grupo de Investigación Choc Izone.

Colombia

Mónica Sofía Rico Ramírez

mricor@unbosque.edu.co

Universidad El Bosque

Grupo de Investigación Choc Izone.

Colombia

\section{Jardín infantil Na'e Dwshu. Un diseño empresarial ambiental, cultural y tecnológico con enfoque pedagógico centrado en la persona, en La Hormiga, Putumayo}

\author{
Jardín infantil $\mathrm{Na}$ e Dwshu. \\ Un environmental, cultural and \\ technological business design \\ with a person-centered pedagogical \\ approach, in The Hormiga, Putumayo
}

\author{
Jardín infantil $\mathrm{Na}$ 'e Dwshu. \\ Um projeto empresarial ambiental, \\ cultural e tecnológico com uma \\ abordagem pedagógica centrada na \\ pessoa, em La Hormiga, Putumayo
}

\begin{abstract}
Resumen
Ante la preocupación por la pérdida de valores en la sociedad actual y la falta de un significado que satisfaga la propia vida del hombre, nace la idea de diseñar un sistema de gestión empresarial bajo el nombre de jardín infantil $\mathrm{Na}^{\prime}$ e Dwshu, proyectado para ofrecer el servicio educativo a niños de dos a cinco años de edad en La Hormiga, Putumayo. Este proyecto se diseña con un enfoque pedagógico centrado en la persona, desde la logoterapia para fomentar, en los niños y sus familias, los valores y el sentido de la existencia humana. Además, se fundamenta en un modelo pedagógico con abordajes ambientales, culturales, tecnológicos y de aproximación científica, para potenciar el desarrollo físico, cognitivo, del lenguaje, emocional y social del niño, con la realización de actividades rectoras de la educación inicial, juego, arte, literatura y exploración del medio.

El diseño del jardín infantil está enmarcado en un entorno de saberes y tradiciones culturales, y en un contexto ambiental, tecnológico y de emprendimiento, con un sistema de gestión empresarial ambiental encaminado a generar impactos sociales positivos en los procesos directivos, administrativos, financieros, y de la comunidad, con el uso eficiente de los recursos naturales y por medio de una gestión responsable que conlleve a generar valor económico, ambiental, cultural y social en la región
\end{abstract}

Palabras clave: desarrollo cognitivo, desarrollo del lenguaje, desarrollo emocional, desarrollo físico, enfoque pedagógico, gestión ambiental, gestión empresarial, modelo pedagógico. 


\begin{abstract}
In the face of the concern for the loss of values in the current society and the lack of a meaning that it satisfies the man's own life, the idea is born of designing a system of managerial administration under the name infantile garden $\mathrm{Na}^{\prime}$ e Dwshu, projected to offer the educational service to children from two to five years of The Ant, Putumayo. This project is designed with a pedagogic focus centered in the person, from the logotherapy to foment, in the children and its families, the values and the sense of the human existence. Also, it is based in a pedagogic model with environmental, cultural, technological boardings and of scientific approach, for enhance the physical development, cognitive, of the language, emotional and social of the boy, making use of the activities rectors of the initial education, game, art, literature and exploration of the means.

The design of the infantile garden is framed in an environment of knowledge and cultural traditions, and in an environmental, technological context and of entrepreneurship, with a system of environmental managerial administration guided to generate positive social impacts in the directive, administrative, financial processes and of the community, making efficient use of the natural resources and by means of a responsible administration that bears to generate economic, environmental, cultural and social value in the region
\end{abstract}

Keywords: cognitive development, language development, emotional development, physical development, pedagogical approach, environmental management, business management, pedagogical model

\section{Resumo}

Dada a preocupação com a perda de valores na sociedade atual e a falta de um sentido que satisfaça a própria vida do homem, nasceu a ideia de desenhar um sistema de gestão empresarial com o nome de Na'e Dwshu kindergarten, projetado para oferece o serviço educativo a crianças entre dois e cinco anos de La Hormiga, Putumayo. Este projeto foi concebido com uma abordagem pedagógica centrada na pessoa, desde a logoterapia até à promoção, na criança e na sua família, dos valores e sentido da existência humana. Além disso, baseiase em um modelo pedagógico com abordagens ambientais, culturais, tecnológicas e científicas, para potencializar o desenvolvimento físico, cognitivo, de linguagem, emocional e social da criança, valendo-se das atividades norteadoras de educação inicial, brincadeira, arte, literatura e exploração do meio ambiente.

A concepção do jardim de infância enquadra-se num ambiente de saberes e tradições culturais, e num contexto ambiental, tecnológico e empresarial, com um sistema de gestão ambiental do negócio que visa gerar impactos sociais positivos nos processos diretivos, administrativos, financeiros e de gestão. a comunidade, fazendo uso eficiente dos recursos naturais e por meio de uma gestão responsável que leve à geração de valor econômico, ambiental, cultural e social na região.

Palavras-chave: desenvolvimento cognitivo, desenvolvimento da linguagem, desenvolvimento emocional, desenvolvimento físico, abordagem pedagógica, gestão ambiental, gestão empresarial, modelo pedagógico. 


\section{INTRODUCCIÓN}

El hombre sufre cada vez más un vacío existencial que resulta difícil de superar debido a la pérdida de referencias y valores que vive la sociedad y afronta su existencia sin una referencia clara de lo que puede ser la vida. Desde esta perspectiva, la logoterapia percibe al hombre como un ser que desea trazarse una vida llena de sentido, de significado frente a las circunstancias de la vida. El sentido no solo debe, sino que también puede encontrarse [1].

Ante esta realidad y porque no existe un modelo pedagógico que promueva el ambiente, la cultura y la tecnología, surge la necesidad de diseñar una propuesta empresarial en el jardín infantil $\mathrm{Na}^{\text {e }}$ Dwshu, con un enfoque pedagógico centrado en la persona, desde la logoterapia, para la formación integral de los niños y la vinculación de sus familias; para fortalecer el aspecto etnocultural, promover la responsabilidad socioambiental y fomentar la investigación y la tecnología, potenciando en el niño las áreas de desarrollo físico cognitivo, emocional, social, y del lenguaje.

Este trabajo es de carácter cualitativo-descriptivo, porque hay una aproximación a la comunidad de La Hormiga, Putumayo, donde se estudia y se describe el estado actual de la educación inicial, y hay un acercamiento al conocimiento de las etnias propias de la región, mediante la entrevista como técnica de estudio del método en mención.

En la investigación, se diagnosticó el estado de la educación en primera infancia, niños entre los dos y los cinco años de edad, en La Hormiga, Putumayo. Se recopiló información y se generaron indicadores de referencia para fortalecer el enfoque y el modelo pedagógico del jardín infantil.

El modelo pedagógico articula las actividades rectoras de la primera infancia, juego, arte, literatura y exploración del medio, las cuales permiten a los niños construir y representar su realidad, así como relacionarse con el mundo, con sus compañeros y maestros. Dichas actividades tienen un lugar protagónico en la educación inicial, dado que potencian el desarrollo de los niños desde la lúdica, la creatividad, la diversión y las interacciones establecidas en la cotidianidad.

En el sistema de gestión empresarial, el jardín infantil $\mathrm{Na}^{\prime}$ e Dwshu aborda el diagnóstico de la gestión empresarial, el plan estratégico, el plan operativo y el sistema de gestión ambiental en sus seis (6) componentes: gestión de educación ambiental, seguridad y salud ocupacional, riesgos, residuos sólidos, recurso del agua y energía.

Finalmente, el jardín infantil $\mathrm{Na}^{\prime}$ e Dwshu se proyecta como una empresa prestadora de servicio educativo a niños de dos a cinco años de La Hormiga, Putumayo, para formar personas íntegras, competentes en el mundo, con calidad humana, con mejores condiciones de vida y capaces de convivir pacíficamente en la sociedad.

\section{MARCO CONTEXTUAL}

\section{La Hormiga, Putumayo}

La Hormiga, es la cabecera municipal del Valle del Guamuez, municipio colombiano ubicado en el departamento del Putumayo. Este municipio cuenta con un área aproximada de $841 \mathrm{~km}^{2}$, de los cuales $129 \mathrm{~km}^{2}$ pertenecen a resguardos de los pueblos indígenas Cofán, Embera Chamí, Nasa y Pastos, principalmente. Toma su nombre del gran río Guamuez, que lo cruza de oeste a este, y que es utilizado por los habitantes de la región como medio de transporte, pesca, y recreación. El principal lugar de atracción es el río La Hormiga para los bañistas, y el sendero ecológico para caminar en familia.

En el Valle del Guamuez, existen varios pueblos indígenas, loscualesestánorganizadosenla“"Asociación de Autoridades Tradicionales Mesa Permanente de Trabajo por el Pueblo Cofán y Cabildos Asociados", organización que los representa políticamente a nivel regional, nacional e internacional, en defensa de los derechos fundamentales de los pueblos indígenas, que le permite la constitución política de Colombia y los tratados internacionales, de igual manera los mandatos del plan de vida y del plan de salva guarda dictado por la corte constitucional mediante el Auto 004 de 2009.

Según el "Modelo educativo propio integrado e intercultural del pueblo Cofán y cabildos Awá, Embera-Chamí, Kichwa, Nasa y Pasto de los municipios Valle del Guamuez, San Miguel y Orito -Putumayo":

1) El Pueblo Cofán (A'l): es ancestral del territorio comprendido desde los ríos Orito, Guamuez, parte del río Putumayo, San Miguel y Aguarico. Hoy, de acuerdo a las divisiones 
político-administrativas, el pueblo Cofán (A'l) se encuentra ubicado en Puerto Asís, Orito, Valle del Guamuez y San Miguel Putumayo, e Ipiales Nariño, en Colombia; y en Ecuador sobre las riberas del río Aguarico. El pueblo Cofán comparte el territorio desde hace más de sesenta años con culturas indígenas provenientes de otras regiones del país como los Nasa, Embera Chamí, Kichwa, Awá y Pastos.

2) El pueblo Kichwa: habita en la frontera a la orilla del río San Miguel. Es un pueblo descendiente de los Incas, de quienes heredaron el idioma quechua, y otros usos y costumbres. De acuerdo con la historia de poblamiento y ocupación del área, los Kichwa argumentan una existencia en la zona de más de 50 años, pero sus ancestros y raíces son ecuatorianos de la zona del río Napo. Al igual que los Cofán son tomadores de yagé, al que denominan Ayahuasca y manejan relaciones armoniosas con la naturaleza.

3) Los indígenas Awá: son un pueblo procedente de Nariño, se consideran de raíces ecuatorianas. Desde hace varias décadas se han dispersado por el Putumayo, su proceso como pueblo indígena en la zona es menor a una década. Han ocupado un espacio territorial cerca al puente internacional sobre el río San Miguel.

4) El pueblo Pasto: está constituido por personas provenientes del departamento de Nariño, del resguardo de Males, quienes llegaron como colonos y hace unos pocos años han recibido su reconocimiento como grupo étnico.

5) Los Embera Chamí: son un grupo étnico proveniente del Chocó y Risaralda, son cultura de la planta de Pilde, sus usos y costumbres de selva húmeda tropical les permite tener una relación sostenible en la Amazonía.

6) El grupo étnico Nasa: proveniente del departamento del Cauca, habla el Nasa Yute y mantienen los usos y costumbres de sus comunidades de origen, en particular el uso de la coca y el tabaco son el sustrato de su cultura[2]

\section{Población infantil de La Hormiga, Putumayo}

De acuerdo con cifras del Sisben de 2017, en La Hormiga, Putumayo, hay un total de ochocientos trece (813) niños entre los dos y cinco años de edad; y según las entrevistas realizadas a los directivos de jardines infantiles y centros de desarrollo infantil de La Hormiga, hay cuatrocientos treinta y nueve (439) niños de estas edades que reciben educación en la primera infancia; por lo tanto, se puede deducir que hay trescientos setenta y cuatro (374) niños de dos a cinco años de edad, por fuera del sistema educativo.

\begin{tabular}{|c|c|c|c|}
\hline \multirow{2}{*}{$\begin{array}{c}\text { Edad } \\
\text { (Años) }\end{array}$} & \multicolumn{3}{|c|}{ Población Infantil } \\
\cline { 2 - 4 } & Municipio & La Hormiga & $\begin{array}{c}\text { La Hormiga } \\
\text { niños de 2 -5 años } \\
\text { de edad }\end{array}$ \\
\hline 0 & 346 & 143 & \\
\hline 1 & 410 & 184 & \\
\hline 2 & 396 & 183 & 183 \\
\hline 3 & 423 & 202 & 202 \\
\hline 4 & 450 & 205 & 205 \\
\hline 5 & 457 & 223 & 223 \\
\hline TOTAL & 2.482 & 1.140 & 813 \\
\hline
\end{tabular}

Tabla I. Apoblación infantil valle del guamuez

Fuente: elaboración previa a partir de los datos del Sisben.

\section{MARCO TEÓRICO}

\section{A. Enfoque centrado en la persona}

El enfoque centrado en la persona [3] resalta un continuo empeño en la confianza y el respeto a la persona; tiene como punto de partida la creencia de que el ser humano está dotado de capacidades de las que puede hacer uso para lograr sus objetivos y metas. La educación centrada en la persona se identifica por ayudar a los estudiantes a convertirse en personas capaces de tener iniciativas propias para la acción y a ser responsables de sus acciones; así mismo a ser capaces de tolerar y ayudar a los demás.

Este enfoque no desconoce la capacidad creadora del hombre, al contrario, cree totalmente en la persona humana y hace énfasis especialmente en el valor y el respeto que merece. La persona es un ser extraordinario y vale la pena centrar en él toda la atención; comprender y entender "el todo" del hombre será imposible, pero se puede tener una aproximación a la realidad de tan compleja magnitud del "ser" y asume que toda persona es distinta, es un mundo diferente, lleno de cualidades, valores, virtudes, capacidades; 
pero también con muchos defectos y desaciertos. Es importante entonces, hablar de las relaciones humanas, las cuales resultan nada fácil de abordar, porque es complejo unir conceptos, pensamientos, sentimientos y creencias en un mundo tan grande; no obstante, se busca el diálogo y mil maneras de lograr unas buenas relaciones humanas, a partir de actitudes que puede desarrollar el ser humano para mejorar la convivencia en la familia y sociedad.

\section{Logoterapia}

"Logos" es una palabra griega que equivale a "sentido", "significado" o "propósito", se centra en el significado de la existencia humana, así como en la búsqueda de dicho sentido por parte del hombre. De acuerdo con la logoterapia, la primera fuerza motivante del hombre es la lucha por encontrarle un sentido a su propia vida. Este sentido es único y específico en cuanto es uno mismo y uno solo quien tiene que encontrarlo; únicamente así logra alcanzar el hombre un significado que satisfaga su propia voluntad de sentido. El hombre, no obstante, es capaz de vivir e incluso de morir por sus ideales y principios [4].

En la actualidad, quizá por la tecnología que avanza cada vez más rápido, o por el afán de adquirir lo material, el ser humano se ha sumergido en ese mundo, muchas veces olvidándose hasta de sí mismo; las redes sociales, por ejemplo, están envolviendo tanto a los niños, adolescentes, jóvenes y hasta a los adultos, en un mundo artificial, que cada vez que salen de ese universo se encuentran con la realidad de la vida; y algunos ya no quieren asumirla, porque es distinta y hay que luchar, esforzarse y batallar para alcanzar lo que parece tan fácil en el mundo virtual. Así, hay adolescentes hoy en día, que no quieren estudiar, no quieren trabajar y no saben qué es y qué será de su vida. Verdaderamente hay un vacío en su existencia.

\section{Educación inicial}

La primera infancia es la etapa del ciclo vital en la que se establecen las bases para el desarrollo cognitivo, emocional y social del ser humano. Comprende la franja poblacional que va de los cero $(0)$ a los seis (6) años de edad [5].

En el proceso de educación inicial, el compromiso debe ser colectivo, una corresponsabilidad entre los que intervienen en el entorno del niño. Los padres de familia son los primeros maestros de sus hijos; su tarea es apoyarlos en el proceso escolar y dar buen ejemplo en el entorno del hogar; no se puede pretender que la educación de los niños se reciba solamente en el jardín infantil. Otra responsabilidad es de los maestros de educación inicial, quienes también deben enseñar con el testimonio y, asumir una educación centrada en la persona, que consideren al niño como persona con valor, que crean en sus capacidades, que facilite un aprendizaje significativo por medio de experiencias nuevas e innovadoras, con la potenciación del sentido de la indagación y la exploración; pero sobre todo conducir a los niños hacia una educación de valores, construir día a día en ellos conductas positivas, por medio de actos repetitivos aceptables, de tal manera que esas buenas conductas se conviertan en hábitos, para formar las virtudes en los niños.

Unos niños formados en virtudes, descubrirán el sentido de la vida, crecerán con habilidades y conocimientos; además, serán fuertes psicológica y emocionalmente. Los valores y principios sembrados en ellos, permitirá que cuando lleguen a la adolescencia y a la juventud tomen caminos aceptables y no se refugien en las drogas, el alcoholismo o lleguen al suicidio.

\section{La familia}

La familia es célula básica de la sociedad. Las funciones de la familia, básicamente, cuidado, socialización y educación son necesarias para el desarrollo humano. Existe la necesidad de reflexionar sobre la identidad de la familia para valorar qué contribución al desarrollo se le puede pedir. Según la Sociología relacional, el discurso discurre más allá del tema de las funciones de la familia. Mostrar qué es la familia constituye un reto educativo en nuestro contexto. Las ideas acerca del sentido de la familia pueden ser motivadoras para que los ciudadanos asuman la imprescindible tarea de hacer familias que cuiden a las personas y a la sociedad [6].

La familia es el depósito de los valores que más profundamente quedan grabados en el espíritu de sus miembros mediante la educación [7].

Otro autor reconocía a la familia como una unidad de apoyo vital para el niño y el papel de los padres a la hora de comprender y alentar el crecimiento y la educación de sus hijos. Ella hablaba a los padres de 
familia sobre la importancia de su papel y llamaba la atención sobre los derechos del niño y la necesidad del respeto mutuo [8].

\section{Cultura}

Definida como un sistema de valores, creencias y de relaciones, se manifiesta mediante hábitos, usos, costumbres y otros aspectos de la cosmovisión propia de los pueblos. Comprende hábitos alimenticios, educación propia, tradiciones, lengua propia, expresiones culturales, medicina tradicional [9], [10].

Según el "Plan de vida del pueblo Cofán y cabildos indígenas del Valle del Guamuez y San Miguel”, uno de los fundamentos de la cultura es el territorio. El territorio para las comunidades indígenas, tiene un gran significado, no se trata solamente del espacio de vida, sino también el espacio donde se desarrollan las relaciones simbólicas. Es decir, la presencia del bosque, la fauna, la flora, los ríos y quebradas, juegan un papel importante dentro de un sistema cosmológico y en el que se sustentan las creencias. El territorio para el pueblo Cofán representa toda la vida, y es la Madre Naturaleza, ya que allí se "cría” y desarrolla la planta sagrada del yagé, "Esta planta es la mejor escuela que se puede tener y la mejor medicina, allí se concentra la sabiduría del pueblo"[11]

\section{Ambiente y desarrollo sostenible}

En la historia se ha tratado de crear conciencia social y ambiental con la necesidad de ponerle fin al deterioro ambiental con el propósito de salvaguardar la vida en el planeta; por ello, a nivel mundial se habla de desarrollo sostenible, el cual considera indispensable el uso racional de la oferta natural, donde el ser humano no tenga que dejar de utilizar los recursos naturales, pero que tampoco se exceda en el uso de ellos hasta el punto de agotarlos.

En el Informe Bruntland, se define el desarrollo sostenible como "el desarrollo que satisface las necesidades del presente sin comprometer la habilidad de las generaciones futuras de satisfacer sus propias necesidades" [12].

\section{Las cinco fuerzas de Porter}

- Es un modelo que facilita un marco de reflexión estratégico para determinar la rentabilidad de una empresa. De ahí, se puede inferir que, el potencial de rentabilidad de una organización está definido por cinco fuerzas, a saber:
- Amenaza de nuevos entrantes: toda industria atractiva que tiene buenos rendimientos atraerá nuevas empresas.

- Amenaza de productos o servicios substitutos: Los productos sustitutos están siempre presentes listos para remplazar los productos de la empresa. Precios bajos de los sustitutos, número de sustitutos en el mercado.

- Rivalidad entre los competidores existentes: interacción entre los competidores de la industria debido a múltiples factores como la concentración de empresas para un mismo mercado y existencia de grupos empresariales.

- Poder de negociación de los proveedores: la capacidad de los proveedores para poner a la empresa bajo presión. Dependencia de pocos proveedores, accesibilidad a las materias primas.

- Poder de negociación de los compradores: la capacidad de los clientes para poner a la empresa bajo presión. Dependencia de unos pocos clientes, grado de dependencia.

La comprensión de las fuerzas competitivas, y sus causas subyacentes, revela los orígenes de la rentabilidad actual de un sector y brinda un marco para anticiparse a la competencia e influir en ella (y en la rentabilidad) en el largo plazo. Una estructura saludable de su sector debería ser tan importante para un estratega como la posición de su empresa. Comprender la estructura de un sector también es clave para un posicionamiento estratégico eficaz. Defender a la empresa de las fuerzas competitivas y moldearlas para su propio beneficio es crucial para la estrategia [13].

\section{Análisis PESTLE}

El análisis PESTLE se hizo popular a partir de la segunda mitad del siglo XX. Describe la necesidad de analizar los factores externos para el éxito de un proyecto o de una organización.

PESTLE, en términos de sus aplicaciones se basa en sus seis parámetros que son políticos, económicos, sociales, técnicos, legales y ambientales. Cada uno de estos aspectos debe ser analizado en el entorno de una organización, para diagnosticar el estado actual y con ello proyectar un plan estratégico, y tomar decisión en beneficio de la empresa. 


\section{METODOLOGÍA}

El enfoque de la investigación es cualitativo, con estudio descriptivo, porque hay una aproximación a la situación actual de la educación en la primera infancia en La Hormiga, Putumayo, y se describen las características estudiadas del estado de la educación inicial en la región. Diferentes autores sostienen que, "con los estudios descriptivos se busca especificar las propiedades, las características y los perfiles de personas, grupos, comunidades, procesos, objetos o cualquier otro fenómeno que se someta a un análisis. La meta del investigador consiste en describir fenómenos, situaciones, contextos y sucesos; esto es, detallar cómo son y se manifiestan" [14].

La investigación también es cualitativa porque permite el acercamiento a la comunidad de La Hormiga, Putumayo, con el estudio de grupos pequeños para diagnosticar el estado de la educación inicial.

Se usó la entrevista como técnica cualitativa de estudio, para conocer la opinión de la población, frente a lo cual, varios autores señalan que la investigación cualitativa estudia grupos pequeños en los cuales sea posible la observación directa por parte del investigador que los estudia. Refiere que a veces esta investigación considera solo unos pocos casos de una categoría social, a los cuales explora en profundidad [15].

El enfoque cualitativo se basa en métodos de recolección de datos no estandarizados ni predeterminados completamente. Tal recolección consiste en obtener las perspectivas y puntos de vista de los participantes (sus emociones, prioridades, experiencias, significados y otros aspectos más bien subjetivos). También resultan de interés las interacciones entre personas, grupos y colectividades. El investigador hace preguntas más abiertas, recaba datos expresados mediante el lenguaje escrito, verbal y no verbal, así como visual, los cuales describe, analiza y convierte en temas que vincula, y reconoce sus tendencias personales [14].

Por medio de esta metodología, además, se realizó la conceptualización cultural de los pueblos indígenas de la región, se parte de la bibliografía y del acercamiento a estas comunidades en la zona.

Como resultado de este trabajo, también se realizó un diagnóstico de la gestión empresarial y ambiental de la organización productiva, el cual se tuvo en cuenta para el diseño de un sistema de gestión empresarial y de un sistema de gestión ambiental del jardín infantil $\mathrm{Na}^{\prime}$ e Dwshu.

Para ello, se construyó un plan estratégico, un plan operativo, el plan de marketing verde del jardín infantil $\mathrm{Na}^{\prime}$ e Dwshu, y un análisis financiero que determina la viabilidad del proyecto.

También, se realizó el diseño de un enfoque pedagógico centrado en la persona desde la logoterapia, y la estructura de un modelo pedagógico que promueve el ambiente, la cultura, la tecnología y un acercamiento al conocimiento científico.

\section{RESULTADOS}

Con base en la metodología de investigación aplicada, se presentan los siguientes resultados, en el marco del sistema de gestión empresarial ambiental:

\section{A. Diagnóstico de la gestión empresarial y ambiental de la organización productiva}

Análisis PESTLE: es una de las metodologías empleadas para contextualizar y diagnosticar el entorno macro del jardín infantil $\mathrm{Na}^{\prime}$ e Dwshu. Con este se hizo posible el diseño del sistema de gestión empresarial.

- Político: la política indígena trata de establecer, en el marco institucional, las iniciativas que propone el plan de vida, el modelo de educación propia, el plan de salva guarda, para un desarrollo concertado entre las autoridades indígenas de acuerdo con la cosmovisión y el gobierno nacional.

El Taita Víctor Quenamá Queta, del pueblo Cofán, afirma: "con esta fe y con este valor, los mayores y las organizaciones indígenas hemos avanzado en la tarea, en el trabajo, en la defensa de nuestros derechos, con base en el plan de vida, el cual da las directrices y el camino a seguir en beneficio de las comunidades indígenas, desde los niños hasta los mayores, para vivir con respeto, tolerancia y en armonía con Dios, con el ser humano y con la naturaleza".

- Económico: los pueblos indígenas del municipio Valle del Guamuez, tienen las chagras tradicionales como base fundamental para cultivar los productos de pan coger. Según el Taita Víctor, la chagra es la forma más ancestral de cultivar 
la tierra mediante los usos y costumbres, con las prácticas culturales y la cosmovisión de los pueblos de la selva. Son espacios de interrelación en aspectos espirituales, culturales, sociales y económicos. Es un espacio de transmisión de conocimiento sobre la tierra y la manera de cultivar los productos autóctonos de la región. También las artesanías que produce el hombre indígena trasmitidas por tradición de padres a hijos, generan ingresos económicos para el sustento familiar.

- Social: "Somos un pueblo de sabedores que le ofrecemos a la humanidad el conocimiento sobre las plantas medicinales, nuestra capacidad de sanar enfermedades corporales y espirituales, basada en la generosidad y en la humildad.
Nuestro conocimiento adquirido desde nuestra planta sagrada del yagé, es un elemento espiritual que orienta nuestras vidas como pueblo y en las ceremonias nos permite proponer un modelo de desarrollo comunitario con pensamiento indígena" [10].

- Tecnológico: el Taita Víctor, dice que, desde la visión indígena, de acuerdo a los usos y costumbres de los pueblos originarios, construían las canoas para transportarse por el rio, elaboraban las bodoqueras o cerbatanas, el arco, la lanza, las trampas, la atarraya y el chinchorro, elementos para cazar; asimismo en el tema de comunicación se usaba el chasqui, el humo, el cacho, la bamba y el yagé que es el internet cultural y espiritual del pueblo Cofán.

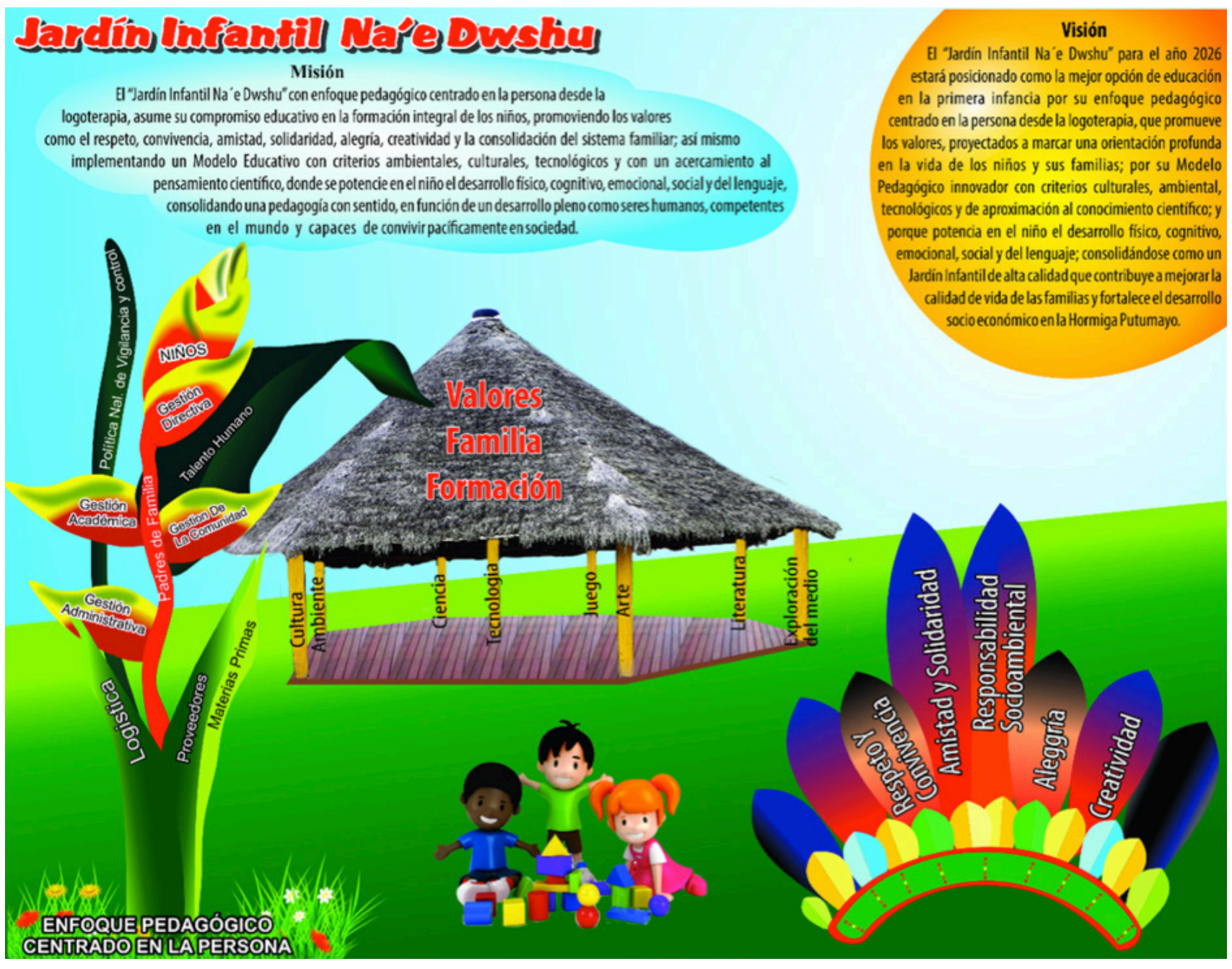

Figura 1. Sistema de gestión empresarial del jardín infantil Na'e Dwshu.

Fuente: elaboración propia. 
“Los pueblos indígenas han venido articulándose al nuevo sistema tecnológico planteado desde occidente, con la finalidad de hacer uso de la televisión, el internet, el celular y las emisoras; de igual manera los elementos para cazar, pero sin olvidar las costumbres culturales de la población indígena que ha sido transmitida de generación en generación", refirió el Taita Víctor Quenamá Queta.

- Legal: la población indígena tiene en cuenta la normatividad vigente, y sus propias normas, de acuerdo a su cosmovisión y creencias.

La Convención sobre los derechos del niño, de 1989 , señala la importancia del respeto de los valores culturales de la comunidad del niño, y el papel crucial de la cooperación internacional para que los derechos del niño se hagan realidad.

El Artículo 29 dice: “Los Estados Partes convienen en que la educación del niño deberá estar encaminada a: (iteral c) Inculcar al niño el respeto de sus padres, de su propia identidad cultural, de su idioma y sus valores, de los valores nacionales del país en que vive, del país de que sea originario y de las civilizaciones distintas de la suya.

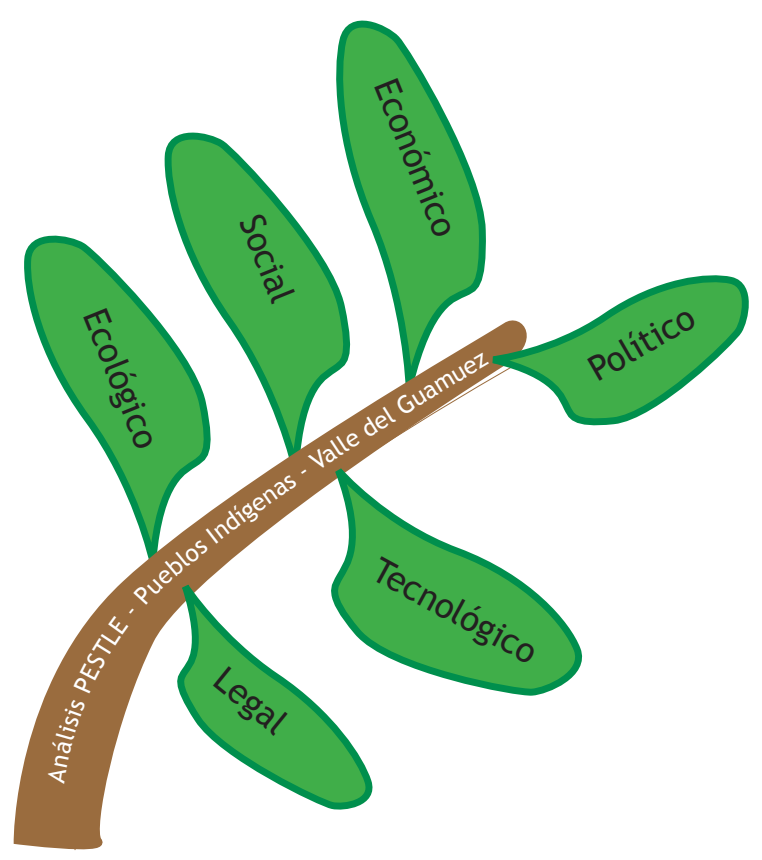

Figura 2. Análisis PESTLE desde el aspecto cultural del Valle del Guamuez.

Fuente: elaboración propia a partir del método PESTLE.
- Ecológico: el Taita Víctor Quenamá, señala que los pueblos indígenas son los agentes de la mayor parte de la diversidad cultural del mundo. El municipio Valle del Guamuez, es una región con un alto nivel de riqueza selvática y biológica cultural, porque viven los pueblos indígenas y son los guardianes de la naturaleza. Las comunidades indígenas velan por mantener un espacio libre de contaminación, por el cuidado y la protección del medio ambiente desde el pensamiento indígena y la armonización entre el ser humano y la madre naturaleza, por ello la "educación propia" está encaminada en el conocimiento ancestral con fundamento para mantener el equilibrio entre el hombre y naturaleza, lo que propicia un desarrollo personal y colectivo basado en la cultura.

Análisis de las cinco fuerzas de Porter: Por medio de este se realiza el diagnóstico o estudio del entorno micro del jardín infantil $\mathrm{Na}^{\prime}$ e Dwshu.

- Nuevos competidores: la razón de ser y las ventajas competitivas, formarán una barrera muy fuerte ante la entrada de nuevos competidores.

- Poder del cliente: los padres de familia tienen varios jardines infantiles para seleccionar; no obstante, se posicionará la marca del jardín infantil $\mathrm{Na}^{\prime}$ e Dwshu, por ser de alta calidad y por su enfoque y modelo pedagógico que hacen la diferencia.

- Poder de los proveedores: los proveedores serán de la región. El jardín infantil seleccionará los mejores costos en la adquisición de materiales e implementos requeridos en la implementación y desarrollo del servicio educativo.

- Amenaza de productos sustitutos: el jardín infantil será la oferta del mejor servicio que sustituya los ya existentes, porque es un establecimiento con valor agregado, enmarcado en el enfoque pedagógico, centrado en la persona desde la logoterapia; con una fuerte razón de ser, lo cual marca la diferencia ante la competencia, lo que permite que se posesione como un jardín infantil fortalecido, que no tiene competencia que lo sustituya.

- Intensidad de la rivalidad: el jardín infantil tiene como rivales a tres centros de desarrollo infantil, de carácter público y tres jardines infantiles de carácter privado. No se competirá con la estrategia del océano rojo, sino del océano 
azul, es decir, no se tratará de superar a los rivales con una competencia sangrienta; El jardín infantil ofrece algo nuevo, diferente; un diseño empresarial ambiental con enfoque pedagógico centrado en la persona, para la formación de los niños y sus familias, lo que promueve las buenas prácticas ecológicas y fortalece la identidad cultural en la región.

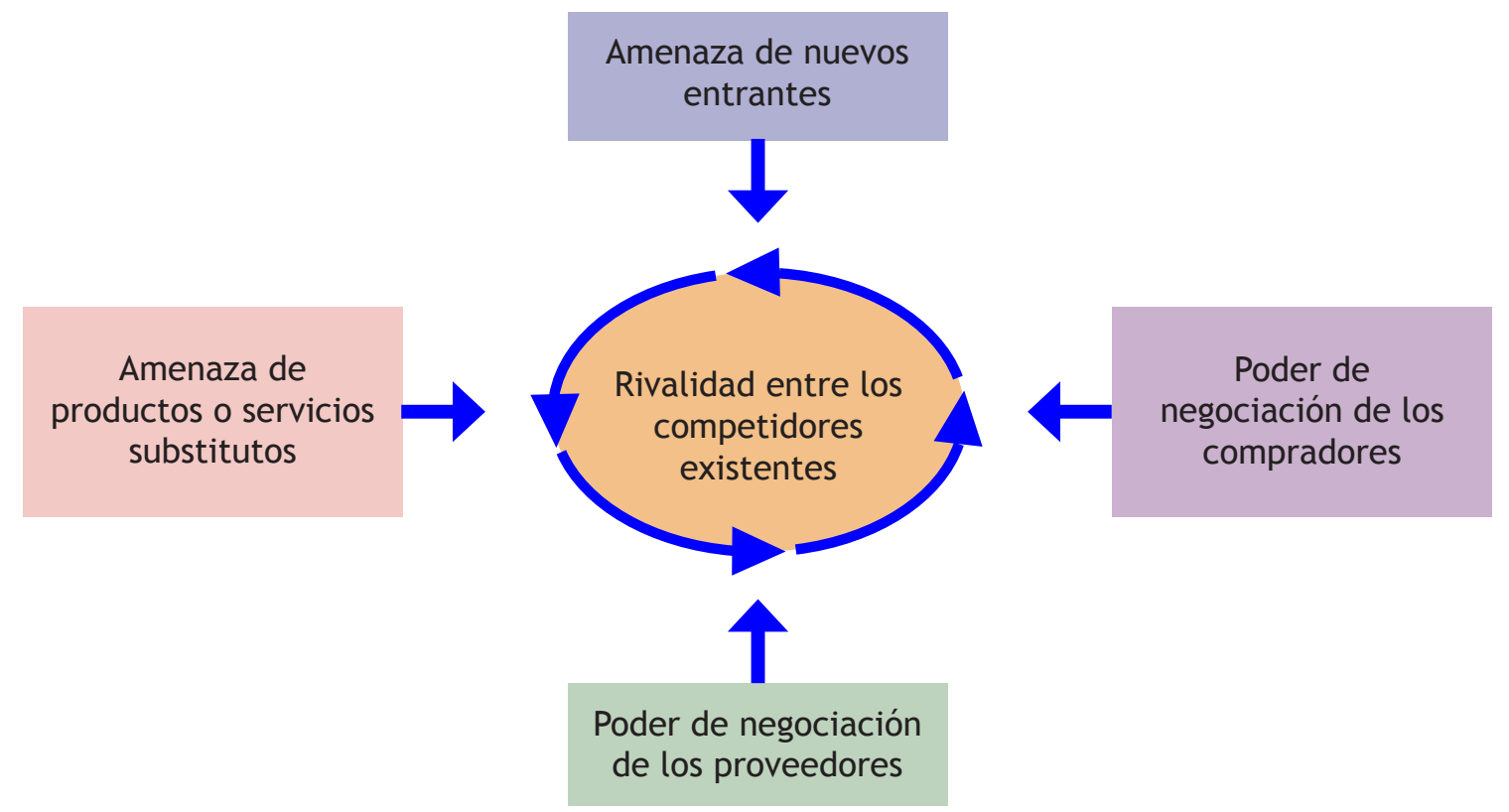

Figura 3. Análisis de las cinco fuerzas de Porter. Fuente: elaboración propia a partir de [13].

\section{Plan estratégico}

El plan estratégico del jardín infantil $\mathrm{Na}^{\prime}$ e Dwshu, consolida la razón de ser, los procesos clave, talento humano, capital tecnológico y capital organizacional.

1) Razón de ser: la razón de ser del jardín infantil, abordada en la misión, visión y valores, se muestran en la figura 4.

2) Los procesos clave: son cuatro los procesos que se establecen como columnas en el sistema de gestión empresarial del jardín infantil, descritos a continuación:

- Gestión directiva: con su misión orientadora y promotora del mejoramiento, tiene como ámbito de acción la institución educativa en su conjunto. La acción de esta gestión se concreta en la organización, diseño, desarrollo y evaluación de una cultura escolar propia, en el marco de la política educativa vigente. Con el liderazgo de su equipo de gestión, la institución se orienta estratégicamente hacia el cumplimiento de su misión y visión.

- Gestión administrativa y financiera: tiene a su cargo todo lo concerniente a los sistemas de información y registro de los estudiantes, el manejo de los recursos financieros, la administración de los recursos humanos y físicos, y la prestación de los servicios complementarios.

- Gestión académica: enfoca su acción en lograr que los estudiantes aprendan y desarrollen las competencias necesarias para su desempeño social, profesional y personal. Tiene como dinamizador principal a la comunidad académica, cuyos aportes en conocimientos, experiencias, innovaciones 0 investigaciones adelantadas por parte de los diferentes agentes educativos 
contribuyen al desarrollo y el mejoramiento de la institución para el logro de las metas y los objetivos propuestos.

- Gestión de la comunidad: incluye la promoción de la participación de la comunidad educativa y la provisión de las condiciones que permitan una sana convivencia entre sus miembros. El ámbito en el que se desarrollan las acciones de esta gestión vincula a todos los actores de la comunidad, a la organización institucional con su entorno, para fortalecer el desarrollo de identidad y sentido de pertenencia con la institución y su proyecto Educativo Institucional (PEI).

3) Talento humano: es el encargado de los procesos pedagógicos, administrativos y de servicios. Constituyen un aspecto clave en la atención integral de los niños, por lo cual, además de sus atributos personales, requieren cumplir ciertas condiciones desde el punto de vista de su formación profesional.

Se requiere el siguiente talento humano para el jardín infantil: directora, auxiliar administrativo, maestras, psicóloga, auxiliar en salud y nutrición, personal de servicios generales y manipuladora de alimentos. Este personal será contratado de acuerdo con el número de niños matriculados; será seleccionado a partir del perfil requerido y preferiblemente que sean de la región. Después de la selección, se realizará inducción y capacitación, y se les pagará honorarios de acuerdo a la ley.

Es importante resaltar que es indispensable la formación para este selecto grupo; una formación fundamentada en primer lugar, en valores y principios. Los educadores son los primeros llamados a interiorizar este enfoque educativo en su vida para que haya congruencia entre lo que vive y lo que pregona a los estudiantes. El maestro tendrá que ser y reflejar autenticidad, honestidad e integridad; que estas virtudes sean dignas de imitar y que permitan una relación maestro-estudiante de respeto y aceptación. De esta manera, el estudiante reconocerá que su educador lo valora, lo tiene en cuenta, cree en sus capacidades y respeta sus opiniones. Así, el proceso pedagógico no será tedioso; el logro será un aprendizaje con sentido para la vida.

Habrá un plan de formación y cualificación del talento humano, de acuerdo al perfil, para dar cumplimiento al enfoque y modelo pedagógico.

\section{4) Capital tecnológico}

- Tecnología del conocimiento: el talento humano deberá tener conocimientos básicos en el manejo de equipos de cómputo, tanto para el trabajo pedagógico como para la entrega de informes. No obstante, será necesaria la cualificación del talento humano en el manejo de las TIC y la importancia de integrarlas desde la primera infancia, ya que "La tecnología en sí misma no es negativa para el desarrollo infantil, es simplemente una herramienta, y como toda herramienta depende de cómo se utilice" [16].

- Tecnología operativa: la tecnología será indispensable, en todo el sistema de gestión empresarial. Este activo intangible es una herramienta muy importante para incrementar la eficiencia y para mantener la ventaja competitiva en un mundo globalizado donde cada día las organizaciones se enfrentan a nuevos retos, nuevos desafíos, nuevas reglas, nuevas tecnologías.

Por esta razón, el jardín infantil estará a la vanguardia con este activo que ayudará a impulsar la organización. Contará con un sistema de información actualizado, ordenado y sistematizado, tanto de manera física, como en el software. Así mismo, será imprescindible el uso de las redes sociales para la promoción del jardín infantil y para ofrecer un buen servicio de información y comunicación a la comunidad.

- Tecnología física: en el jardín infantil se aplicará el conocimiento para el desempeño de las actividades, donde se incluirán diversos equipos, entre ellos: computador, tablet, televisor, video beam. Además, para disminuir la entropía, el jardín infantil instalará paneles solares y sensores de movimiento de energía y agua.

5) Capital organizacional: el jardín infantil $\mathrm{Na}^{\prime} \mathrm{e}$ Dwshu estará a la vanguardia de los procesos de cambio educativo, para llevar a cabo la estrategia de posicionamiento en el mercado de las instituciones educativas. Además, el jardín infantil, sella un compromiso con la primera infancia; un compromiso que asegura que los niños pueden crecer y desarrollarse integralmente con un buen sistema educativo y con el acompañamiento de los padres de familia; para ello busca orientar acciones con énfasis en la formación del niño como persona con valor y sentido, como eje del desarrollo humano y de la educación en edad inicial. 

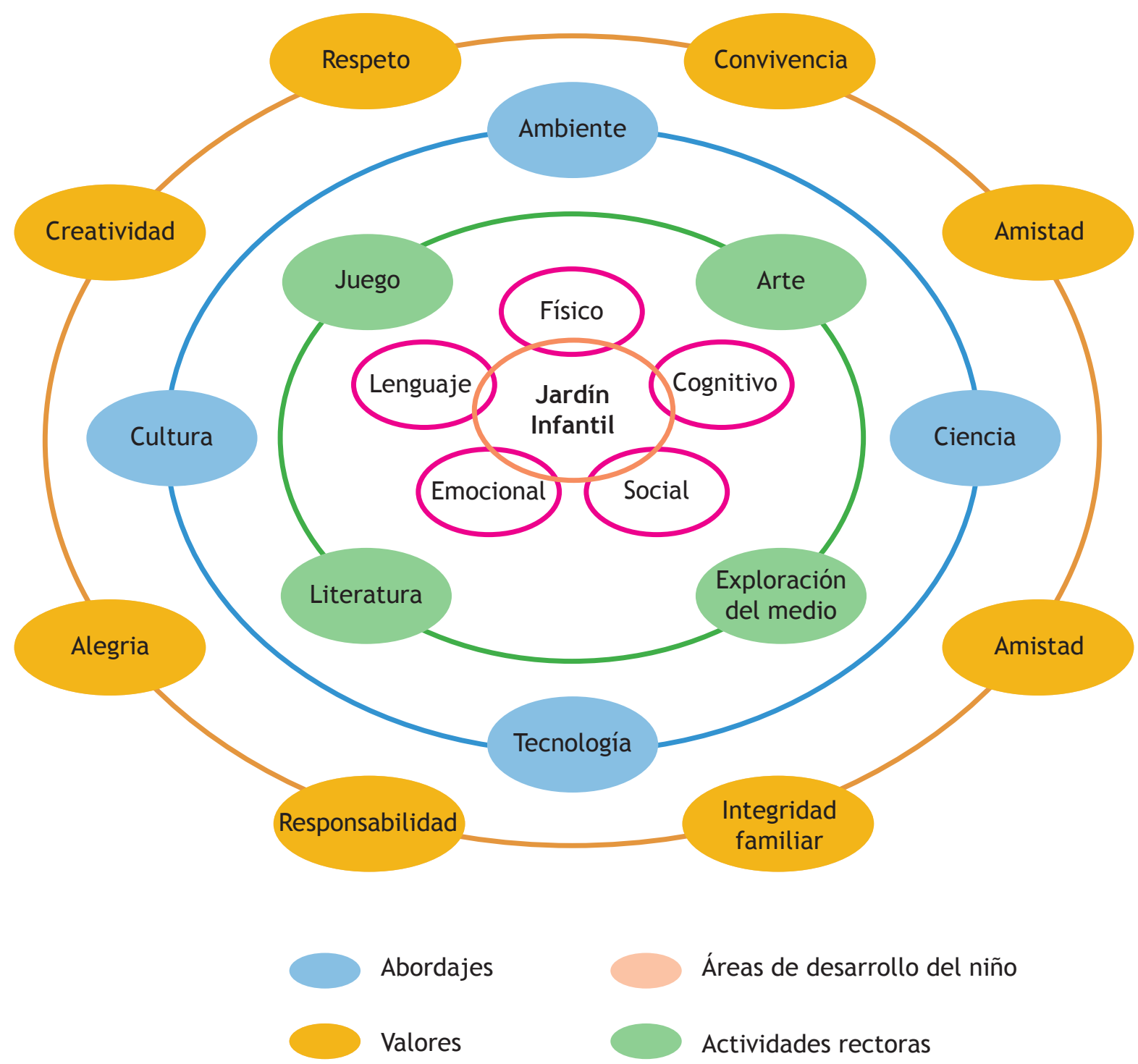

Áreas de desarrollo del niño

Actividades rectoras

Figura 4. Esquema - Enfoque y modelo pedagógico del jardín infantil Na'e Dwshu.

Fuente: elaboración propia.

\section{Proyecto Educativo Institucional (PEI)}

El Proyecto Educativo Institucional (PEI), del jardín infantil se construirá en el marco del enfoque pedagógico centrado en la persona, desde la logoterapia, para la formación de niños de dos (2) a cinco (5) años y sus familias, con valores como el respeto, convivencia, amistad, solidaridad, integridad familiar, responsabilidad socio-ambiental, alegría y creatividad.

El PEl deberá detallar los cuatro procesos clave mencionados anteriormente, gestión directiva, gestión administrativa y financiera, gestión académica y gestión de la comunidad. Este proyecto, articulará el enfoque pedagógico centrado en la persona desde la logoterapia y el modelo pedagógico que se explica en las siguientes líneas.

\section{Modelo pedagógico}

El modelo pedagógico se consolida con abordajes ambientales, culturales, tecnológicos y de aproximación al pensamiento científico. También, se registran las áreas de desarrollo del niño y las actividades rectoras o pilares de la educación inicial: 
1) Abordaje ambiental: el jardín infantil cuenta con procesos pedagógicos para promover la conservación y protección de los recursos naturales, así como el fomento de buenas prácticas ecológicas para aportar el tan anhelado desarrollo sostenible. Para cumplir con este propósito se cuenta con un sistema de gestión ambiental, representado en la figura 5 .

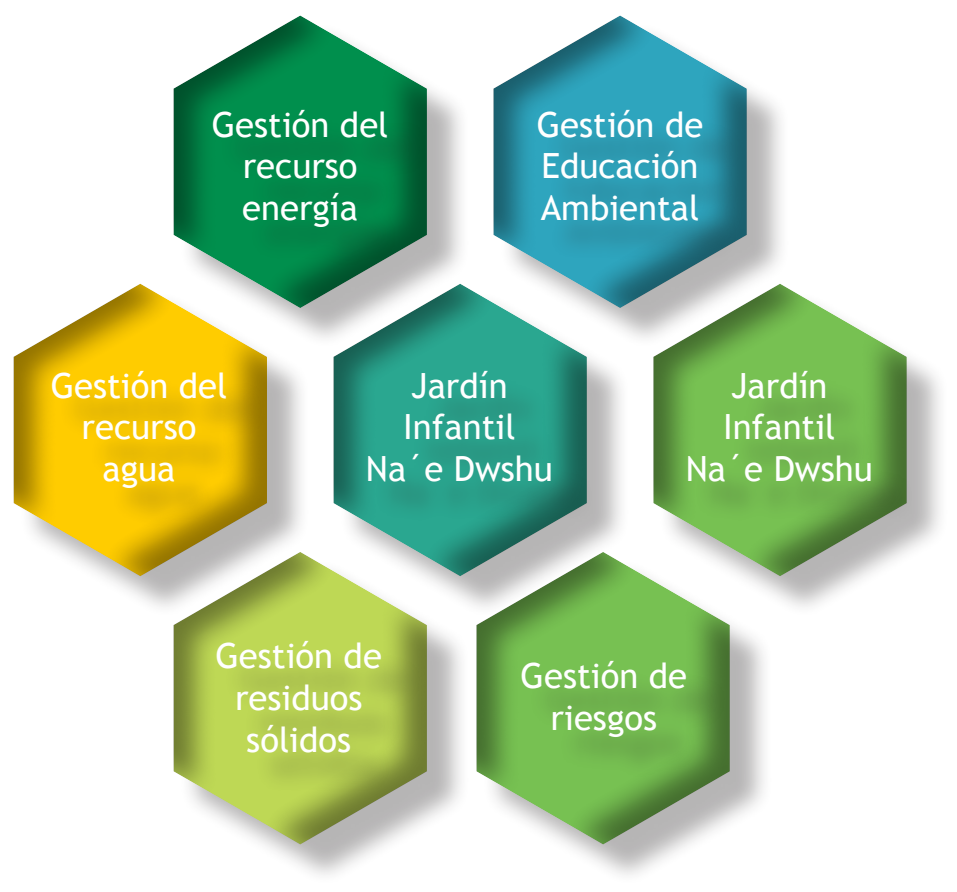

Figura 5. Sistema de gestión ambiental del jardín infantil Na'e Dwshu. Fuente: elaboración propia.

A continuación, se puntualizan algunos programas, temas y actividades para desarrollar con los niños y, en algunos casos, con padres de familia:

- Proyectos pedagógicos para la conservación del medio ambiente.

- Creación de zonas verdes, chagra tradicional y huerta medicinal como espacios de enseñanza-aprendizaje.

- Actividades de reciclaje.

- Cuidar y cultivar las plantas.

- Cuidar los animales.

- Separación de residuos sólidos.

- Formación en responsabilidad social y sensibilidad ecológica.

2) Abordaje cultural: principalmente, se tiene como base la zona geográfica donde se desarrolla el proyecto, puesto que La Hormiga,
Putumayo, es una región donde habitan varias comunidades indígenas, ellas son: Cofán, Nasa, Embera, Kichwa, Pastos y Awá. Por ello, con el modelo pedagógico se fomentará y se promoverá el respeto por la diversidad cultural. En el proceso de enseñanza aprendizaje, se desarrollarán las siguientes actividades y temáticas:

- Programas culturales donde participen los niños, los padres de familia y la comunidad con dramatizados, canciones, coplas, entre otros, alusivos a las tradiciones o a los usos y costumbres de los pueblos indígenas de la región.

- Música autóctona: conocer sus tradiciones musicales, aprender canciones en varios idiomas indígenas, elaborar instrumentos musicales que utilizan las comunidades indígenas, con materiales reciclados.

- Visitas a los taitas y abuelas de los pueblos indígenas con el fin de conocer sobre su cultura e interactuar con ellos. 
- Invitar a un abuelo, abuela o a un hablante de la lengua nativa, para que narre un mito o un cuento, en lengua castellana, pero también se exprese en su lengua materna.

- Literatura tradicional: mitos, leyendas, cuentos de los pueblos indígenas.

- Juegos tradicionales, danzas de las comunidades indígenas.

- Rituales, usos y costumbres de los pueblos indígenas.

- Platos típicos, trajes típicos.

- Artesanías propias.

3) Abordaje de aproximación al pensamiento científico: se promoverá en la educación inicial el acercamiento al conocimiento científico que permita desarrollar la investigación, y que parte de la curiosidad innata de los niños, para que exploren el mundo de manera significativa, desarrollen el pensamiento, resuelvan problemas, experimenten, descubran y fortalezcan todas sus capacidades. Para cumplir con este propósito, se desarrollarán proyectos pedagógicos, bajo el nombre "Ateswye", que significa "conocer" en lengua indígena Cofán. Las temáticas para abordar estos proyectos, tendrán como punto de partida, los intereses de los niños. Cada proyecto deberá tener un objetivo claro de aprendizaje. Para el desarrollo, los maestros podrán realizar las siguientes actividades:

- Salidas de campo con el acompañamiento de los padres de familia, donde los niños tengan la oportunidad de indagar, investigar, consultar, descubrir, pensar, crear y resolver todas sus preguntas. Así, el niño podrá construir conocimiento significativo para su vida, porque es adquirido por medio de la experiencia y con base a sus propias necesidades.

- Actividades pedagógicas en la chagra tradicional y en la huerta medicinal.

- Actividades recreativas, artísticas o culturales, donde se potencie el conocimiento científico.

- Crear mundos de aventuras, para que los niños potencien su imaginación, su creatividad, desarrollen sus capacidades y adquieran aprendizajes significativos.

- Actividades donde se haga uso de todos los sentidos, para que los niños puedan ver, sentir, palpar, oler, degustar, y mediante la experiencia logren descubrir y construir conocimiento.
- Estos proyectos se desarrollarán haciendo uso de las actividades rectoras de la primera infancia: juego, arte, literatura y exploración del medio.

4) Abordaje tecnológico: No se puede desconocer que en la actualidad los niños son considerados nativos digitales, y el mundo globalizado de hoy exige cada día más el uso de las tecnologías. Por ello, es necesario hacer uso de las TIC como una herramienta en el proceso de enseñanza aprendizaje. El uso deberá ser adecuado, de acuerdo a la edad del niño, y con objetivos de aprendizaje previamente establecidos. Las TIC se podrán usar de la siguiente manera:

- Hay mucho material en internet, recursos multimedia, videos, juegos, apps, cuentos, imágenes, entre otros, que pueden ser usados de manera propicia para potenciar la adquisición de conocimientos en los niños y generar estrategias de autoaprendizaje, por medio de la investigación, información y consultas para el logro de aprendizajes significativos.

- Videos pedagógicos, juegos con enseñanzas positivas.

- Música con temáticas formativas.

- Aplicaciones infantiles.

- Conocimiento de las partes de un computador.

- Se realizarán talleres de formación a padres de familia sobre el uso adecuado de las tecnologías, para que ellos comprendan las ventajas de estas herramientas cuando son usadas apropiadamente, pero también entiendan las consecuencias de un inadecuado manejo.

5) Áreas de desarrollo del niño: en primer lugar, se tiene en cuenta las ocho (8) etapas de desarrollo psicosocial del hombre, según Erik Erikson, las cuales señalan cómo la persona, desde su nacimiento va desarrollando sus capacidades a partir de las necesidades propias de crecimiento y cómo los padres o cuidadores, acompañan y apoyan esos procesos que son recompensados con la confianza de los hijos depositada en ellos; así mismo refiere sobre la autonomía que el niño va adquiriendo, pero también sobre la etapa de la vergüenza, y de cómo afloran los sentimientos, afectos y emociones.

Hay etapas en las que aparecen los celos, rivalidades infantiles, fracasos, culpas, ansiedades y 
se va dejando poco a poco el apego a los progenitores, pues ya se debe ir a la escuela, lugar donde el niño puede llegar a sentirse inferior porque su personalidad, etnia, color de piel, religión, estatura, contextura física, en fin, es diferente a los otros. Luego llega la pubertad, la adolescencia, la etapa de identificarse por lo que es, el enamoramiento y la búsqueda de valores sociales que guían su identidad. De esta manera se va preparando para la intimidad, algunos tienen estas experiencias, pero otros prefieren el aislamiento. Posteriormente llega la madurez y con ello el deseo de guiar a la nueva generación. Finalmente, llega la vejez, algunos sienten que han hecho bien el trabajo, otros, al contrario, sienten remordimientos y temor a la muerte [17].

A través del modelo pedagógico, se potenciará en el niño, las áreas del desarrollo físico, cognitivo, social, emocional y del lenguaje, reconociendo que el desarrollo infantil es un proceso de perfeccionamiento de las capacidades de cada niño, desde su individualidad, a medida que crece tanto en el aspecto físico como en la dimensión cognitiva, social, emocional y del lenguaje. Al crecer va fortaleciendo su aspecto corporal, adquiere habilidades y destrezas, aprende a comunicarse, a controlar sus emociones, a formar amistades, a interactuar socialmente y desarrolla sus capacidades cognitivas.

6) Actividades rectoras: el modelo pedagógico articula las cuatro actividades rectoras, también llamadas pilares de la educación inicial:

- El juego: es fundamental en el proceso formativo de los niños, es la manera más fácil y coherente de enseñar el conocimiento de forma divertida y práctica. La lúdica prácticamente está impregnada en el ser del niño, es algo innato, muchas veces no se necesita enseñarle a jugar, él mismo hace un juego desde lo más simple hasta lo increíble. Es importante que en los jardines infantiles se vele por rescatar los juegos tradicionales.

- La literatura: en los primeros años de vida es fundamental, es donde el niño manifiesta su lenguaje, su manera de comunicarse. En esta etapa, el niño es capaz de leer desde su propia imaginación, con sólo ver unas cuantas imágenes es suficiente. El niño crea cuentos, deja volar su imaginación, inventa desde lo desconocido; él es capaz de escribir una historia aún sin saber leer ni escribir, con sus grandes garabatos escritos se siente en capacidad de decirle al adulto lo que eso significa, y lo hace con tanta propiedad y seguridad que, sin duda, el más intelectual reconocería su habilidad.

- Exploración del medio: indiscutiblemente el niño aprende explorando, indagando, preguntando de todo lo que lo rodea; esa es su manera natural de conocer y aprender de la vida, del mundo en que vive. El jardín infantil debe brindarle los espacios y actividades adecuadas para que él pueda interactuar con el ambiente, con los materiales naturales como con aquellos objetos elaborados por el ser humano. El maestro debe siempre estar listo a responder a las inquietudes de los niños por pequeñas que sean sus preguntas.

- Arte: se debe potenciar la creatividad de los niños mediante diversas actividades artísticas, donde los niños puedan desarrollar y fortalecer sus habilidades y destrezas. Con el arte se puede llevar a los niños a vivir diversas aventuras, por ejemplo, desarrollar programas culturales donde participen con dramatizados, canciones, coplas, entre otros; organizar actividades de música, donde todos hacen parte de una orquesta y cada uno tiene un instrumento musical, los cuales han sido previamente elaborados con materiales reciclados. Otra actividad importante es, conocer los instrumentos musicales que utilizan las comunidades indígenas, conocer sus tradiciones musicales, las danzas, las artesanías, entre otros.

\section{A. Sistema de gestión ambiental de la organización productiva}

El sistema de gestión ambiental del jardín infantil $\mathrm{Na}^{\prime}$ e Dwshu, se desarrolla teniendo en cuenta la Norma ISO 14001, la cual "proporciona a las organizaciones un marco con el cual proteger el medio ambiente y responder a las condiciones ambientales cambiantes, siempre guardando el equilibrio con las necesidades socioeconómicas" [18].

Esta norma señala los siguientes objetivos del sistema de gestión ambiental: contribuye a la protección del medio ambiente de una forma preventiva; mitiga los impactos ambientales negativos y los efectos secundarios según las condiciones ambientales de la empresa; ayuda a la empresa a cumplir con la legislación; controla la forma en la que se diseñan los productos y servicios que ofrece la organización; consigue beneficios financieros y 
operaciones que pueden resultar de aplicar alternativas ambientales relacionadas que fortalecen el posicionamiento del mercado; comunica la información ambiental a las partes interesadas.

- Gestión de educación ambiental: brindar educación en términos ambientales a los niños, padres de familia, talento humano y comunidad, a partir de lo establecido por la Unesco en 2014, que señala que la educación desempeña un papel esencial en el desarrollo sostenible: crear un mejor mañana para todos.

- Gestión de seguridad y salud ocupacional: ayudar a proteger la organización y los empleados, mediante acciones dirigidas a preservar, mejorar y reparar la salud de las personas en su trabajo.

- Gestión de riesgos: es parte de la gobernanza y el liderazgo, y es fundamental en la manera en que se gestiona la organización en todos sus niveles. Esto contribuye a la mejora de los sistemas de gestión. Es parte de todas las actividades asociadas con la organización e incluye la interacción con las partes interesadas [19].
- Gestión de residuos sólidos: tener en cuenta la Resolución 754 de 2014, por la cual se adopta la metodología para la formulación, implementación, evaluación, seguimiento, control y actualización de los planes de gestión integral de residuos sólidos.

- Gestión del recurso agua: actuar de acuerdo con el Decreto 2811 de 1974, que promueve el uso sostenible de los recursos naturales e impulsa la implementación, mantenimiento y desarrollo de programas para uso eficiente y ahorro de agua y energía.

- Gestión del recurso energía: cumplir la normativa, como la Ley 697 de 2001, reglamentada por el Decreto Nacional 3683 de 2003, mediante la cual se fomenta el uso racional y eficiente de la energía.

\section{B. Plan de marketing verde}

A continuación, se describe el proceso de marketing del jardín infantil Na'e Dwshu, de manera resumi$\mathrm{da}$, teniendo en cuenta que los detalles se encuentran a lo largo de todo el proyecto:

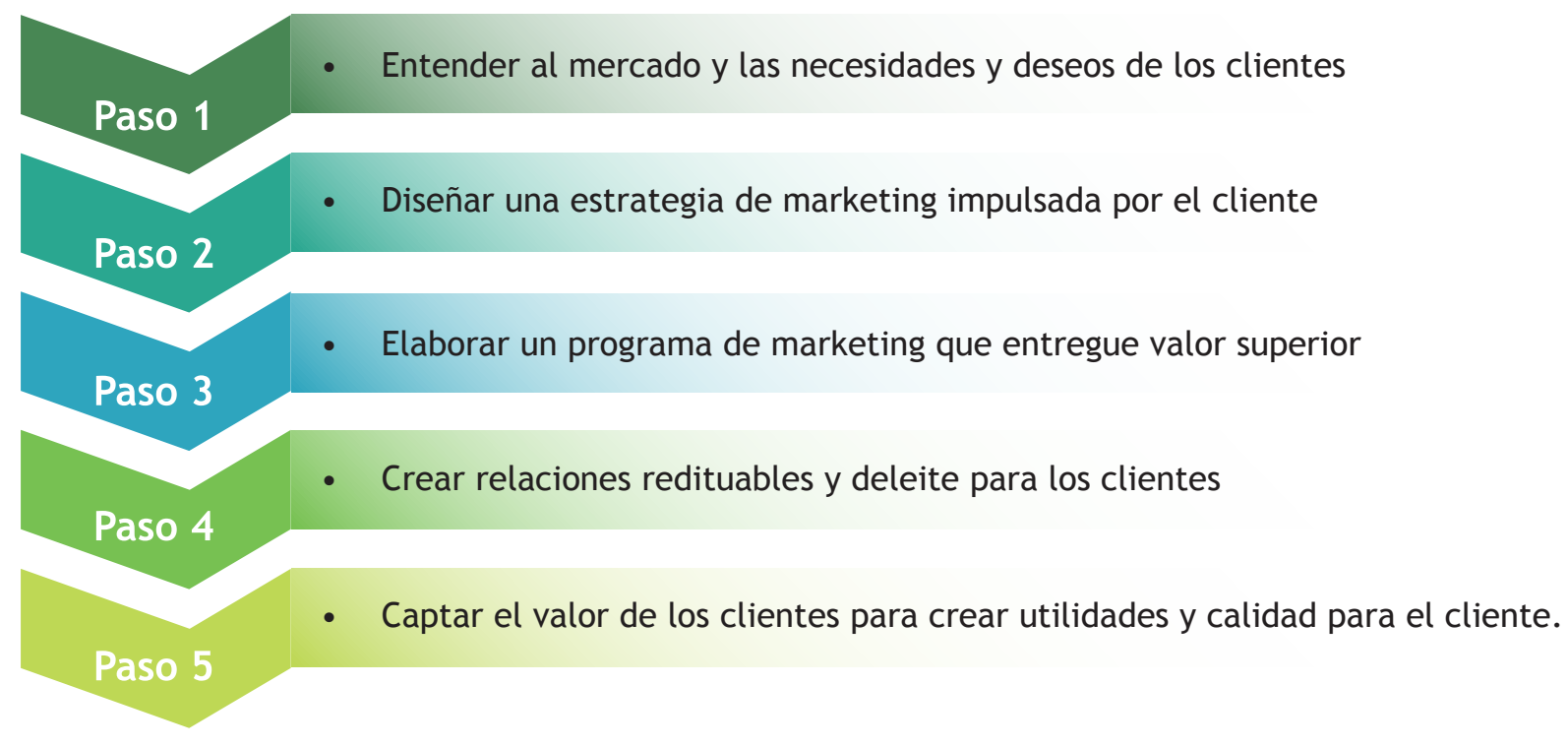

Figura 6. Pasos en el proceso del plan de marketing. Fuente: elaboración propia. 
- Paso 1. Identificación de la necesidad: la necesidad que satisface el jardín infantil $\mathrm{Na}^{\prime}$ e Dwshu es la atención y el servicio educativo a niños de primera infancia, niños entre los dos y cinco años de edad. Los padres de familia de estos niños requieren el servicio de un jardín infantil confiable y de calidad donde puedan dejar sus hijos con seguridad, mientras ellos van a sus trabajos.

- Paso 2. Elaboración de estrategias de acercamiento a los padres de familia teniendo en cuenta la necesidad identificada, para que perciban el valor del servicio: Se tendrá en cuenta la segmentación del mercado en su aspecto geográfico, demográfico y psicográfico. De igual manera, como ventaja competitiva el jardín infantil $\mathrm{Na}^{\prime} \mathrm{e}$ Dwshu se posicionará e impondrá su marca por su ventaja competitiva, la cual se fundamenta en un sistema empresarial con enfoque pedagógico centrado en la persona que potencia la confianza, el respeto y las capacidades de los niños como seres humanos con valor y sentido, con la integración de la familia en el proceso de formación de sus hijos, quienes contribuirán en la formación de personas capaces de convivir con respeto, comprensión y tolerancia en relación con el ambiente natural, social y cultural.

- Paso 3. Desarrollo de programas que puedan ayudar a acometer las estrategias de la fase anterior: aquí se analizan las once (11) Ps: Price, Promotion, Product, Place, People, Process, Physical, Environment, personalisation, Peer To Peer, Participation, Predictive Models. Además, se tendrán en cuenta aspectos como: posicionamiento de la marca, calidad de la materia prima y el tema de los diseños.

- Paso 4. Determinación de las estrategias de relacionamiento que se tendrán con los clientes: en este aspecto es importante la buena atención en el servicio, tener clara la razón de ser de la Institución, así como un plan de actividades formativas, recreativas y culturales.

- Paso 5. Metodologías de captación del valor de los clientes: en este paso, es necesario tener presente la forma de captación de los clientes y la identificación del perfil de ellos.

\section{Evaluación financiera}

Se realizó la evaluación financiera del jardín infantil $\mathrm{Na}^{\prime}$ e Dwshu, empresa proyectada para prestar el servicio educativo a niños de dos (2) a cinco (5) años de edad de La Hormiga, Putumayo, con el fin de determinar la viabilidad del proyecto. Para ello se estableció, a cinco (5) años, un presupuesto de ventas, de costos y de gastos, para luego determinar el Estado de resultados y con ello poder realizar el flujo de efectivo. Con estos datos, se logró calcular el valor presente neto (VPN), la tasa interna de retorno (TIR) y el WACC (weighted average cost of capital) o costo promedio ponderado del capital (CPPC).

\section{Balance general}

\begin{tabular}{|c|c|c|c|c|c|c|}
\hline \multirow{2}{*}{$\begin{array}{l}\text { BALANCE } \\
\text { GENERAL }\end{array}$} & \multicolumn{6}{|c|}{ Años (miles de pesos) } \\
\hline & 0 año & 1 año & 2 año & 3 año & 4 año & 5 año \\
\hline \multicolumn{7}{|l|}{ ACTIVO } \\
\hline Caja & 3.000 & 649 & 13.943 & 68.692 & 72.569 & 151.641 \\
\hline Bancos & & 0 & 0 & 0 & 0 & 0 \\
\hline $\begin{array}{l}\text { Cuentas por } \\
\text { cobrar }\end{array}$ & & 0 & 0 & 0 & 0 & 0 \\
\hline \multicolumn{7}{|l|}{ Inventario } \\
\hline $\begin{array}{l}\text { Total Activo } \\
\text { Corriente }\end{array}$ & 3.000 & 649 & 13.943 & 68.692 & 72.569 & 151.641 \\
\hline Activo Fijo & 16.000 & 16.000 & 17.893 & 285.422 & 288.905 & 292.058 \\
\hline $\begin{array}{l}\text { Deprecia- } \\
\text { ción }\end{array}$ & 0 & 2.213 & 4.615 & 7.270 & 10.374 & 13.793 \\
\hline $\begin{array}{l}\text { Activo Fijo } \\
\text { Neto }\end{array}$ & 16.000 & 13.787 & 13.278 & 278.151 & 278.531 & 278.265 \\
\hline Total Activo & 19.000 & 14.436 & 27.221 & 346.843 & 351.100 & 429.906 \\
\hline
\end{tabular}

PASIVO

\begin{tabular}{l|r|r|r|r|r|r}
\begin{tabular}{l|r|r|r|r} 
Cuentas por \\
Pagar
\end{tabular} & & 0 & 0 & 0 & 0 & 0 \\
\hline $\begin{array}{l}\text { Obligaciones } \\
\text { Bancarias }\end{array}$ & 0 & 0 & 0 & 265.000 & 212.000 & 159.000 \\
\hline $\begin{array}{l}\text { Impuestos } \\
\text { por Pagar }\end{array}$ & & 0 & 4.219 & 19.418 & 25.303 & 51.846 \\
\hline Total Pasivo & 0 & 0 & 4.219 & 284.418 & 237.303 & $\mathbf{2 1 0 . 8 4 6}$ \\
\hline
\end{tabular}

\begin{tabular}{|c|c|c|c|c|c|c|}
\hline \multicolumn{7}{|l|}{ PATRIMONIO } \\
\hline $\begin{array}{l}\text { Aporte } \\
\text { de Socios }\end{array}$ & 78.000 & 78.000 & 78.000 & 78.000 & 78.000 & 78.000 \\
\hline \multicolumn{7}{|l|}{$\begin{array}{l}\text { Reserva } \\
\text { Legal }\end{array}$} \\
\hline $\begin{array}{l}\text { Utilidad del } \\
\text { Periodo }\end{array}$ & -59.000 & -4.564 & 8.566 & 39.423 & 51.372 & 105.263 \\
\hline $\begin{array}{l}\text { Utilidades } \\
\text { o Pérdidas } \\
\text { ejercicios } \\
\text { anteriores }\end{array}$ & & -59.000 & -63.000 & -54.998 & -15.575 & 35.797 \\
\hline $\begin{array}{l}\text { Total } \\
\text { Patrimonio }\end{array}$ & 19.000 & 14.436 & 23.002 & 62.425 & 113.797 & 219.060 \\
\hline $\begin{array}{l}\text { Total Pasivo } \\
\text { y Patriminio }\end{array}$ & 19.000 & 14.436 & 27.221 & 346.843 & 351.100 & 429.906 \\
\hline $\begin{array}{l}\text { Ecuación } \\
\text { patrimonial }\end{array}$ & 0 & 0 & 0 & 0 & 0 & 0 \\
\hline
\end{tabular}

Tabla II. Balance General

Fuente: elaboración propia. 


\section{Perfil del VPN}

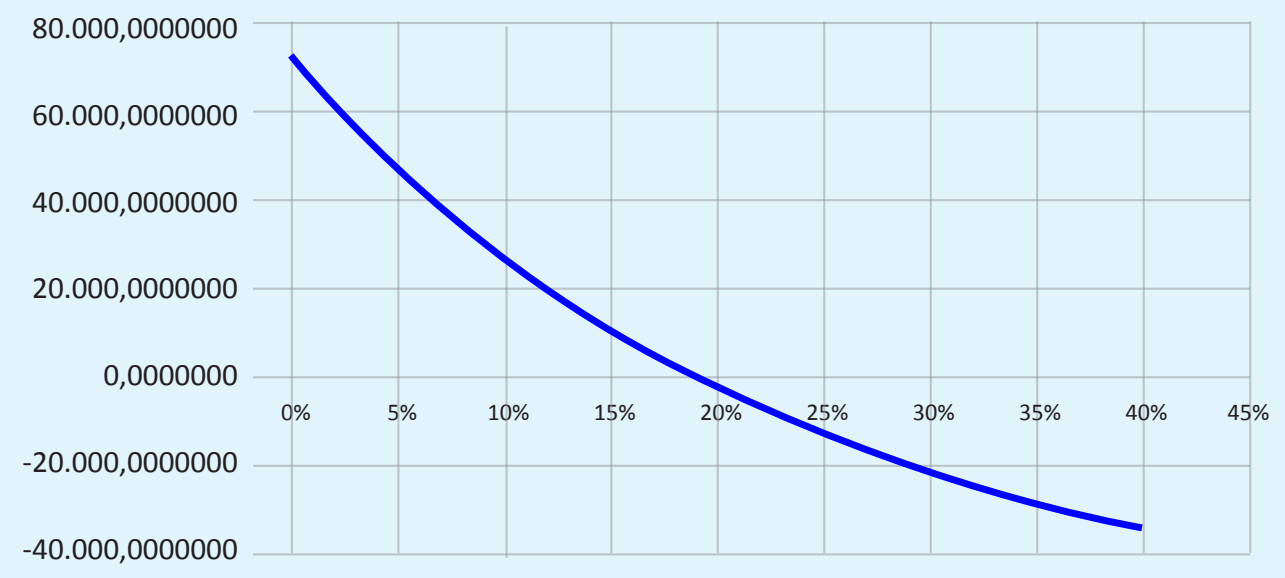

Figura 7. Perfil de VPN.

Fuente: elaboración propia.

\begin{tabular}{|c|c|}
\hline WACC & VPN \\
\hline $0 \%$ & $73.641,0667631$ \\
\hline $1 \%$ & $67.803,2450036$ \\
\hline $2 \%$ & $62.263,8235845$ \\
\hline $3 \%$ & $57.004,3407976$ \\
\hline $4 \%$ & $52.007,6613279$ \\
\hline $5 \%$ & $47.257,8684398$ \\
\hline $6 \%$ & $42.740,1659015$ \\
\hline $7 \%$ & $38.440,7886835$ \\
\hline $8 \%$ & $34.346,9215696$ \\
\hline $9 \%$ & $30.446,6249114$ \\
\hline $10 \%$ & $26.728,7668379$ \\
\hline $11 \%$ & $23.182,9613055$ \\
\hline $12 \%$ & $19.799,5114347$ \\
\hline $13 \%$ & $16.569,3576386$ \\
\hline $14 \%$ & $13.484,0300985$ \\
\hline $15 \%$ & $10.535,6051864$ \\
\hline $16 \%$ & $7.716,6654740$ \\
\hline $17 \%$ & $5.020,2630040$ \\
\hline $18 \%$ & $2.439,8855316$ \\
\hline $19 \%$ & $-30,5745286$ \\
\hline $20 \%$ & $-2.396,8486875$ \\
\hline
\end{tabular}

\section{Punto de equilibrio}

\begin{tabular}{|c|r|}
\hline \multicolumn{2}{|c|}{ ESTADO DE RESULTADOS } \\
\hline Ventas & 11.218 .114 \\
\hline (-) Costos fijos & 6.427 .676 \\
\hline (-) Costos variables & 4.790 .438 \\
\hline (=) utilidad & - \\
\hline Punto Equilibrio & 30 \\
\hline
\end{tabular}

Tabla IV. Punto de equilibrio Fuente: elaboración propia.

\section{VPN, TIR y WACC}

\begin{tabular}{|c|r|}
\hline WACC & $18 \%$ \\
\hline VPN & $\$ 2.440$ \\
\hline TIR & $19 \%$ \\
\hline
\end{tabular}

Tabla V. VPN, TIR y WACC Fuente: elaboración propia.

Tabla III. Perfil del VPN

Fuente: elaboración propia. 
Con el anterior análisis financiero se pudo determinar la viabilidad del diseño empresarial ambiental del jardín infantil $\mathrm{Na}^{\prime}$ e Dwshu.

\section{ANÁLISIS DE RESULTADOS}

La sociedad de hoy sufre ante la crisis de valores, principios y virtudes, que han llevado a la pérdida del sentido de la vida y por ende a la violencia y a las conductas negativas, que afectan directamente a la persona y en consecuencia a la sociedad. La educación no puede ser ajena a esta realidad; se requiere una educación desde la primera infancia no centrada en la transmisión de conocimientos, sino una educación centrada en la persona, que promueva la adquisición de buenas conductas y que ayude al ser humano a encontrar el sentido de la vida, para que logre sus sueños y se consoliden familias estables y funcionales - como base fundamental de la sociedad.

Con este proyecto hubo un acercamiento a la comunidad, para conocer el estado de la educación inicial en la primera infancia en La Hormiga, Putumayo. Para ello, se realizó una entrevista semiestructurada a las coordinadoras y directoras de los Centros de Desarrollo Infantil (CDI) y jardines infantiles. Las entrevistas permitieron recoger información del aspecto pedagógico, cultural, ambiental y empresarial de cada establecimiento educativo.

La información recolectada permitió determinar que, aunque se enseñan valores y se habla del buen trato hacia los niños, ninguno cuenta con un enfoque pedagógico centrado en la persona, ni refieren la importancia de la formación respecto al valor de la vida, que propicie el encuentro del sentido de la vida en los niños y padres de familia, para evitar las conductas negativas como drogadicción, alcoholismo, suicidio, violencia intrafamiliar y otros que afectan a la sociedad.

Se verificó que, en los establecimientos educativos de primera infancia, poco se vincula a los padres de familia en la formación de sus hijos; ellos, aunque participan de programaciones y ayudan en algunos trabajos de los niños, la mayoría no asisten a los talleres de capacitación y es difícil conformar la escuela para padres.

Con la entrevista a Taita Víctor Quenamá, del pueblo Cofán, y el levantamiento de información sobre las comunidades indígenas de la región, se pudo confirmar que existen cinco (5) pueblos indígenas asentados en el Valle del Guamuez, los Cofán, Nasa, Embera Chamí, Awá y Pastos; sin embargo, se evidenció que, en la educación inicial no se fortalece la cultura ancestral; se desconocen las tradiciones, su historia, gastronomía, artesanías propias, traje típico, entre otros usos y costumbres de los pueblos indígenas; tampoco se integran estrategias y programas, en el modelo pedagógico, que garanticen el conocimiento de los pueblos ancestrales de la región y el fortalecimiento de la cultura ante la diversidad cultural del entorno.

Se pudo determinar, con la información recolectada, que, en los Centros de Desarrollo Infantil (CDI) y jardines infantiles, aunque, mediante actividades pedagógicas, se promueve la conservación del ambiente no existe un sistema de gestión ambiental, donde se brinde educación a niños, talento humano y padres de familia sobre desarrollo sostenible, se consolide la gestión eficiente del recurso agua y energía, la gestión de seguridad y salud ocupacional, la gestión de riesgos y la gestión de residuos sólidos.

La infraestructura y los espacios pedagógicos, recreativos, deportivos y zonas verdes, son pequeños, reducidos e insuficientes para prestar un servicio adecuado, acorde a la edad de los niños, y para garantizar una educación integral donde se pueda incluir fácilmente la lúdica, el arte, la literatura y la exploración del medio, como actividades rectoras de la educación inicial.

En el modelo pedagógico establecido en cada establecimiento educativo de primera infancia, poco se promueve la aproximación al pensamiento científico y el uso de las TIC; no se realizan actividades encaminadas a potenciar la investigación y la tecnología. No existen capacitaciones a maestros y padres de familia sobre el uso eficiente de las TIC; y el uso que se hace de estas, es insuficiente.

Por otra parte, se pudo evidenciar que, los CDI y jardines infantiles de La Hormiga, no cuentan con un sistema de gestión empresarial, pues, aunque tienen establecido en el proyecto educativo institucional y en el plan operativo de atención integral, la misión, visión, valores y objetivos de la educación inicial, no cuentan con un plan estratégico y operativo, no realizan un análisis del entorno macro, ni del entorno micro de la organización, tampoco hacen análisis DOFA.

De acuerdo a cifras del Sisben, de los ochocientos trece (813) niños, entre los dos y cinco años de 
edad, que hay en La Hormiga, Putumayo, cuatrocientos treinta y nueve (439) están vinculados a uno de los tres Centros de Desarrollo Infantil (CDI), de carácter público, o a uno de los tres jardines infantiles, de carácter privado. Es decir, que hay trescientos setenta y cuatro (374) niños, de dos (2) a cinco (5) años de edad, por fuera del sistema educativo.

Con lo anterior, se puede inferir que, el jardín infantil Na'e Dwshu, al entrar a operar en la región, podrá brindar soluciones a los déficit encontrados en el estado actual de la educación inicial, y podría posicionar su marca por su enfoque pedagógico centrado en la persona, desde la logoterapia, fundamentado con un modelo pedagógico que promueve el ambiente, la cultura, la tecnología y un acercamiento a la ciencia; y que involucra las actividades rectoras: juego, arte, literatura y exploración del medio para garantizar una educación integral, con la atención de las necesidades y el desarrollo físico, cognitivo, emocional, social y del lenguaje de los niños en La Hormiga, Putumayo.

\section{CONCLUSIONES}

El Estado colombiano, al comprometerse nacional e internacionalmente con una educación inicial, reconoce que la formación desde la edad inicial es determinante en el desarrollo integral del niño; que la familia, la comunidad y la escuela son agentes y responsables de ella, y que son necesarios los entornos para que sea una realidad.

Uno de los mayores problemas que enfrenta la sociedad actual, es que carece de valores y principios que orienten al ser humano a vivir dignamente, con respeto, y que conlleven a convivir de manera tolerante en la sociedad. A diario se ve en el entorno y se escucha en las noticias, conductas llenas de odio, violencia y egoísmo. Ante esta realidad, se debe pensar en una educación, desde la primera infancia, centrada en la "esencia del ser", que vincule a las familias, que promueva la adquisición de buenos hábitos y que encamine al ser humano a encontrar el sentido de la vida, para evitar la delincuencia, drogas, suicidios y toda clase de males que abaten a la sociedad.

El diseño empresarial ambiental del jardín infantil $\mathrm{Na}^{\prime}$ e Dwshu, se consolida como una empresa con enfoque pedagógico centrado en la persona, desde la logoterapia, para la prestación del servicio educativo a niños de dos (2) a cinco (5) años de edad, de La Hormiga, Putumayo, donde se da prioridad a la formación de la "esencia del ser", se considera a los niños como personas con valor y sentido, y con muchas capacidades; también, se promueve la adquisición de buenos hábitos, los cuales se alcanzan con la repetición de buenos actos, que es precisamente como se consolidan las virtudes, tan necesarias en la sociedad.

El jardín infantil Na'e Dwshu, está diseñado para apoyar y propiciar la formación de la familia como eje fundamental en la transmisión de valores, puesto que es en la familia, donde el niño aprende la noción de ser humano, de ser persona, donde aprende los hábitos esenciales que regirán toda su vida; por ello es necesario que se afiancen los vínculos familiares y afectivos y se propicie entornos enriquecidos, de confianza, credibilidad y ejemplo para los niños y la sociedad.

El jardín infantil Na'e Dwshu está fundamentado en un modelo educativo que promueve el ambiente, la cultura, la tecnología y una aproximación a la ciencia, con la integración de actividades rectoras de la educación inicial: juego, arte, literatura y exploración del medio para responder a las necesidades y el desarrollo físico, cognitivo, social, emocional y del lenguaje del niño.

Promueve el ambiente por medio de un sistema de gestión ambiental, empleado para implementar la política ambiental de la organización, con el propósito de generar hábitos de conservación del medio ambiente con iniciativas propias y actividades orientadas a su preservación.

Fortalece la cultura, con el reconocimiento de la importancia y el valor que tienen las comunidades étnicas, mayormente las asentadas en el municipio Valle del Guamuez: Cofán, Embera Chamí, Nasa, Awá y Pastos. El modelo educativo promueve la identidad cultural, el conocimiento ancestral de usos y costumbres, de la gastronomía y las artesanías propias, de los juegos y la literatura tradicional, de la lengua materna y la diversidad cultural.

Potencia un acercamiento a la ciencia y la tecnología como elementos claves y presentes en la vida del ser humano, que deben desarrollarse desde un ejercicio de formación temprana, con el acercamiento del niño a este tipo de conocimientos y el aprovechamiento de la capacidad innata de indagación, para que pregunte, investigue, descubra y adquiera herramientas básicas para desenvolverse a futuro, por medio de experiencias directas con el entorno y las áreas verdes construidas para tal fin. 
El diseño de la infraestructura del jardín infantil $\mathrm{Na}$ 'e Dwshu, es campestre, con abordajes ambientales y culturales. Cuenta con todas las áreas requeridas para la educación inicial, con el área directiva, administrativa, zonas verdes, deportivas y recreativas, amplias y adecuadas para la primera infancia, donde fácilmente se pueden integrar las actividades rectoras: juego, arte, literatura y exploración del medio.

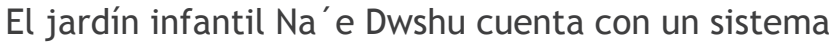
de gestión empresarial, que parte de un diagnóstico por medio del análisis PESTLE, el análisis de las cinco (5) fuerzas de Porter y el análisis DOFA, los cuales constituyen la base para la formulación del plan estratégico, donde se incluye la razón de ser, los procesos clave, el capital organizacional y el factor diferenciador de la organización; para finalmente diseñar el plan operativo, el análisis financiero y el plan de marketing verde.

Con el análisis financiero se pudo determinar la viabilidad del diseño empresarial ambiental del jardín infantil $\mathrm{Na}^{\prime}$ e Dwshu, dirigido a niños de dos (2) a cinco (5) años de edad, con la visión de establecerse como la mejor opción de educación en la primera infancia por su enfoque pedagógico centrado en la persona desde la logoterapia, que promueve los valores de los niños y las familias; por su modelo pedagógico innovador con abordajes culturales, ambiental, tecnológicos y de aproximación científica, y porque potencia en el niño el desarrollo físico, cognitivo, emocional, social y del lenguaje; y se consolida como un diseño empresarial de alta calidad que contribuiría a mejorar la calidad de vida de las familias, y a fortalecer el desarrollo socio económico en La Hormiga, Putumayo.

\section{REFERENCIAS}

[1] A. Mariñez, El sentido de la vida en la obra de Viktor Frankl, Madrid, Entre línea editores, 2003 [En línea]. Disponible en: https:// books.google.com.co/books?id=r-hXao-ZR9sC\&lpg=PP1\&dq=inauthor\%3A\%22Antonio\%20Mar\%C3\%AD\%C3\%B1ez\%22\&hl=es\&pg=$\mathrm{PP} 1 \# \mathrm{v}=$ onepage\&q\& $\mathrm{f}=$ false

[2] Fundación Zio A’I, “Modelo educativo propio integrado e intercultural del pueblo Cofán y cabildos Awá, Emberachamí, Kichwa, Nasa y Pasto de los municipios Valle del Guamuez, San Miguel y Orito - Putumayo.” 2010.
[3] S. C. Cloninger, Teorías de la personalidad. México, Pearson, 2002 [En línea]. Disponible en: https://books.google.com.co/books?i$\mathrm{d}=8081 \mathrm{kic5J5AC \& lpg=PP1 \& dq=Teor \% C3 \% A-}$ Das\%20de\%20la\%20personalidad\&hl=es\&p$\mathrm{g}=\mathrm{PA} 5 \# \mathrm{v}=$ onepage\& $\mathrm{q}=\mathrm{ROGER} \mathrm{f}=\mathrm{false}$

[4] V. E. Frankl, El hombre en busca de sentido. Barcelona, Herder, 1985.

[5] A.M. Quintero. “Modelos de políticas públicas de Colombia, en beneficio de las familias", Rev. Katálysis, vol.14, no.1, pp. 98-111, 2011 [En línea]. Disponible en: https://www.scielo.br/scielo.php?pi$\mathrm{d}=\mathrm{S} 1414-49802011000100013 \&$ script $=$ sci_arttext\&tlng=es. https://doi.org/10.1590/ S1414-49802011000100013

[6] A. Bernal-Martínez, "La identidad de la familia: un reto educativo", Perspectiva Educacional, vol. 55, no. 1, pp. 114-128, 2016 [En línea]. Disponible en: http:// www. perspectivaeducacional.cl/index. $\mathrm{php} /$ peducacional/article/view/289. doi: 10.4151/07189729-Vol.55-Iss.1-Art.289

[7] J. Yepes Stork, R. Aranguren-Echevarria, Fundamentos de antropología. un ideal de la excelencia humana. España, Eunsa, Ediciones Universidad de Navarra, 2001.

[8] L. Britton, Jugar y aprender con el método Montessori: guía de actividades educativas desde los 2 a los 6 años. España, Paidos, 2017.

[9] E. Martínez, “Comenius”. [En línea]. Disponible en: http://educomunicacion.es/figuraspedagogia/0_comenius.htm. [Accedido: 04-mayo- 2018].

[10] Asociación Mesa Permanente Del Pueblo Cofán y Cabildos indígenas del Valle del Gumuez, San Miguel y Orito -Putumayo. Plan de salva guarda del pueblo Cofan - Ingi Atesw'Phama Nuña'He, 2010.

[11] Fundación Zio-A'I, Plan de vida del pueblo Cofán y cabildos indígenas del Valle Del Guamuez y San Miguel, 2002.

[12] A. Martínez, J. P. Figueroa, "Evolución de los conceptos y paradigmas que orientan la gestión ambiental ¿Cuáles son sus limitaciones 
desde lo glocal?", Revista Ingenierías Universidad de Medellín, vol. 13, no. 24, pp. 13-27, 2013 [En línea]. Disponible en: https: / /www. researchgate. net/publication/317499951_ Evolucion_de_los_conceptos_y_paradigmas_ que_orientan_la_gestion_ambiental_cuales_ son_sus_limitaciones_desde_lo_glocal.

[13] M. Porter, Las cinco fuerzas competitivas que le dan forma a la estrategia. Estados Unidos, Harvard Business School Publishing, 2008 [En línea]. Disponible en: https://utecno. files.wordpress.com/2014/05/las_5_fuerzas_competitivas-_michael_porter-libre.pdf

[14] M. Casas, "Introducción a la metodología de la investigación en bioética: sugerencias para el desarrollo de un protocolo de investigación cualitativa interdisciplinaria", Acta bioeth, vol.14, no.1, pp. 97-105, 2008 [En línea]. Disponible en: http://dx.doi. org/10.4067/S1726-569X2008000100013.

[15] J. Zanardini. Revista de la universidad católica 'Nuestra Señora de la Asunción. Estudios Paraguayos, vol. XXVIII, no. 1 y 2, 2010 [En línea]. Disponible en: https://books.google. com.py/books?id=nA0mDwAAQBAJ\&printse- $c=$ frontcover\&source=gbs_ge_summary_r\&$\mathrm{cad}=0 \# \mathrm{v}=$ snippet $\& \mathrm{q}=$ briones\& $\mathrm{f}=$ false

[16] E. González, Introducción temprana a las TIC: Estrategias para educar en un uso responsable en educación infantil y primaria. España, Ministerio de Educación y Ciencia, 2007 [En línea]. Disponible en: https://sede. educacion.gob.es/publiventa/PdfServlet?p$\mathrm{df}=\mathrm{VP1} 2288$. pdf\&area $=\mathrm{E}$.

[17] E. Erikson, Infancia y sociedad. New York, Hormé, 1987 [En línea]. Disponible en: https: / / www.academia.edu/31099902/Erikson_Infancia_y_Sociedad_8_Edades_de_La_ Vida. ISBN 950.618.000.8 pp. 223-244.

[18] Y.C. Ortiz, "El sistema de gestión ambiental bajo NTC-ISO 14001:2015 para una institución de educación superior desde la planificación y control operacional", Revista Signos, vol. 10, núm. 1, pp. 127-137, 2018. [En línea]. Disponible en: https: / / dialnet.unirioja.es/servlet/articulo?codigo $=6726320$.

[19] “Norma Internacional - ISO 31000:2018", 2018 [En línea]. Disponible en: https: / /www. iso.org/obp/ui\#tiso:std:iso:31000:ed-2:v1:es 